\title{
A comparison of modified eversion endarterectomy versus classical endarterectomy in the surgical treatment of carotid artery stenosis
}

\author{
Mahmut Kış (D), Mahir Merdanoğlu (D), Mehmet Balkanay (D) \\ Department of Cardiovascular Surgery, Kartal Koşuyolu Yüksek Ihtisas Training and Research Hospital, Istanbul, Turkey
}

Received: October 15, 2020 Accepted: November 05, 2020 Published online: November 13, 2020

\begin{abstract}
Objectives: In this study, we aimed to compare the modified eversion method versus classical carotid endarterectomy in the treatment of carotid artery stenosis.

Patients and methods: A total of 112 patients ( 85 males, 27 females; mean age $64.8 \pm 9.5$ years; range, 40 to 82 years) who underwent carotid endarterectomy in our hospital between January 2009 and December 2011 were retrospectively analyzed. The patients were divided into two groups according to the method used as the modified eversion group $(n=27)$ and classical endarterectomy group ( $n=85)$. Doppler ultrasound of 62 patients who could be reached among these patients were evaluated and compared in terms of early results of restenosis.

Results: There was no statistically significant difference between the two groups in terms of intraoperative morbidity, mortality, and complications. While there was no mortality in the modified eversion technique, postoperative subcutaneous hematoma occurred in one (3.7\%) patient and revision was applied, and morbidity in the form of right hemiplegia was observed in another patient (3.7\%). In classical endarterectomy, mortality was observed in four $(4.7 \%)$ patients. One $(1.2 \%)$ patient underwent subcutaneous hemorrhage revision, and morbidity in the form of right hemiplegia was observed in another patient (1.2\%). There was no statistically significant difference between the two groups in terms of early results of restenosis. Severe stenosis was found in the arteries undergoing endarterectomy in one patient ( $4.8 \%$ vs. $2.4 \%)$ in each group.

Conclusion: The modified eversion method used in our clinic is as effective as classical carotid endarterectomy. This method should be considered an alternative to the classical endarterectomy technique.
\end{abstract}

Keywords: Carotid artery stenosis, endarterectomy, modified eversion technique.

In countries with ischemic stroke, it is the disease group that ranks third in terms of cause of mortality, while ranking the first in terms of long-term morbidity. Carotid artery stenosis (CAS) accounts for $20 \%$ of all ischemic strokes. ${ }^{[1]}$ In symptomatic carotid artery patients with severe stenosis, carotid endarterectomy (CEA) is recommended as the primary treatment for the prevention of stroke and its complications, ${ }^{[2-5]}$ as well as prioritized over other treatments in asymptomatic patients with severe stenosis. ${ }^{[6-8]}$ There are differences between surgical techniques in CEA, which has such an important place in the treatment of carotid artery disease. In addition, there are differences in the same techniques such as whether to use shunts and whether to use patches (synthetic or native).

In the present study, we aimed to compare the modified eversion endarterectomy (MEE) and the classical CEA method, which are among the CEA methods performed in our hospital.

\section{PATIENTS AND METHODS}

The medical records of a total of 112 patients (85 males, 27 females; mean age $64.8 \pm 9.5$ years; range, 40 to 82 years) who underwent CEA between January 2009 and December 2011 in our hospital were retrospectively analyzed. Data including age, sex, body mass index, smoking and alcohol use, diabetes, hypertension, hyperlipidemia, renal failure, contralateral carotid artery lesion, peripheral artery disease, coronary artery disease, previous

Corresponding author: Mahmut Kış, MD. Kartal Koşuyolu Yüksek İhtisas Eğitim ve Araştırma Hastanesi Kalp ve Damar Cerrahisi Kliniği, 34865 Kartal, İstanbul, Türkiye.

Tel: +90 506 - 2219293 e-mail: mahmutkismd@gmail.com

\section{Citation:}

Kış M, Merdanoğlu M, Balkanay M. A comparison of modified eversion endarterectomy versus classical endarterectomy in the surgical treatment of carotid artery stenosis. Cardiovasc Surg Int 2020;7(3):163-169. 
cerebrovascular accident (CVA), operation type, postoperative CVA, use of shunt, and graft usage were recorded. Control carotid Doppler ultrasound (DUS) was performed in 62 patients who could be reached among this patient group. This examination was applied to each patient in the radiology department using the same Doppler device $\left(\operatorname{Logic}^{\circledR} 9\right.$ Color Duplex Scan; General Electric Medical Systems, WI, USA) with a 10-L probe by a single radiologist. Intraoperative cross-clamp time, graft and shunt usage, operative data, postoperative mortality and morbidity data of the patients were recorded. The patients were divided into two groups according to the method used as the MEE group $(n=27)$ and classical CEA group $(\mathrm{n}=85)$.

A written informed consent was obtained from each patient. The study protocol was approved by the Kartal Koşuyolu Yüksek Ihtisas Training and Research Hospital Ethics Committee. The study was conducted in accordance with the principles of the Declaration of Helsinki.

\section{Surgical technique}

\section{Classical CEA technique}

Following appropriate disinfection and sterile covering under general anesthesia, with a vertical incision, an incision is made along the anterior medial line of the sternocleidomastoid muscle, from the two fingers above the clavicle to the corner of the chin. Dissection is continued subcutaneously along the medial of the sternocleidomastoid muscle. Then, the platysma is dissected. The internal carotid artery (ICA) is explored 3 to $5 \mathrm{~cm}$ distal from the bifurcation. The external carotid artery (ECA) is dissected up to $2 \mathrm{~cm}$ to distal and freed. If bradycardia occurs due to carotid body stimulation, $2-\mathrm{mL}$ lidocaine is injected. After exploration, $100 \mathrm{IU} / \mathrm{kg}$ of intravenous heparin is administered to systemically heparinize the patient. The main carotid artery (MCA), ICA, and ECA are individually wrapped with rubber tapes. Firstly ICA, then ECA, and lastly MCA are clamped with the vascular clamp. The MCA is incised from the bifurcation toward the ICA with a No.11 scalpel. Arteriotomy is lengthened with the Potts scissors. Endarterectomy is performed using microsurgical dissectors by finding the plane between the atherosclerotic plaque and the vessel wall. The plaque is pulled to superior part in proximal direction, and the tunica-media separation is dissected and continued toward the ICA.
The plaque part, which extends toward the ECA, is dissected circumferentially by eversion and removed from the artery. Arteriotomy is closed with a 6/0 monofilament (prolene) using continuous suture technique. Before tying the suture knot, the ECA clamp is opened and closed, allowing air in lumen to escape. After tying the knot, first ECA, then MCA and lastly ICA clamps are taken, respectively. Once bleeding is controlled, 1 Hemovac drain is placed. The subcutaneous tissue and skin are closed properly.

\section{Modified eversion endarterectomy technique}

In this technique, the same method as in classical CEA is applied until MCA, ECA, and ICA clamping. After the cross-clamp, the incision extending from the common carotid artery (CCA) to the ICA is moved forward to the plaque, and the plaque is not opened. By proceeding from the plane between the plaque and the vessel wall as a whole, the plaque is removed first from the ECA, then the CCA, and finally the ICA by everting it. In this method, the lumen is not entered to and no shunt is used. The closure procedure can be made with a patch or primary incision, as in the classical CEA method. The order of air evacuation and lifting the cross-clamps before closing the last stitches is the same as in the classical CEA.

\section{Statistical analysis}

Statistical analysis was performed using the SPSS for Windows version 15.0 software (SPSS Inc., Chicago, IL, USA). Descriptive data were expressed in mean \pm standard deviation $(\mathrm{SD})$, median (min-max) or number and frequency. The Student's t-test was used in comparison of quantitative data to compare normally distributed parameters between the two groups. The chi-square test and Fisher's exact chi-square test were used to compare qualitative data between the groups. A $p$ value of $<0.05$ was considered statistically significant.

\section{RESULTS}

Of a total of 112 patients, the intraoperative results of both methods and early period restenosis results of 62 patients who attended to the follow-up visits were compared. While the MEE was applied to 27 (24.1\%) patients, CEA method was applied to 85 (75.9\%) patients. Baseline demographic characteristics of the patients are shown in Table 1.

According to the method used in the operation, there was no statistically significant difference between 


\begin{tabular}{|c|c|c|c|c|c|c|c|}
\hline & & e den & $\begin{array}{c}\text { Table } 1 \\
\text { caphic charact }\end{array}$ & ristics & atients & & \\
\hline & Modi & eversic & hethod $(n=27)$ & Clas & endart & tomy $(n=85)$ & \\
\hline & $\mathrm{n}$ & $\%$ & Mean $\pm S D$ & $\mathrm{n}$ & $\%$ & Mean \pm SD & $p$ \\
\hline Age (year) & & & $60.4 \pm 11.0$ & & & $67.4 \pm 8.3$ & $0.001^{* *} \dagger$ \\
\hline Body mass index $\left(\mathrm{kg} / \mathrm{m}^{2}\right)$ & & & $26.3 \pm 4.7$ & & & $28.1 \pm 3.7$ & $0.044^{*} \dagger$ \\
\hline Sex & & & & & & & $0.800 \ddagger$ \\
\hline Male & 20 & 74.1 & & 65 & 76.5 & & \\
\hline Female & 7 & 25.9 & & 20 & 23.5 & & \\
\hline Smoking & 17 & 63.0 & & 39 & 45.9 & & $0.122 \ddagger$ \\
\hline Alcohol use & 3 & 11.1 & & 7 & 8.2 & & $0.702 \neq$ \\
\hline
\end{tabular}

the rates of diabetes, hypertension, hyperlipidemia, chronic renal failure, presence of stenosis in the contralateral carotid artery, and other peripheral artery disease ( $p>0.05)$. According to the method used in the operation, there was no statistically significant difference between the incidence of coronary artery

\begin{tabular}{|c|c|c|c|c|c|}
\hline \multicolumn{6}{|c|}{$\begin{array}{c}\text { Table } 2 \\
\text { Additional diseases }\end{array}$} \\
\hline & \multicolumn{2}{|c|}{ Modified eversion method $(n=27)$} & \multicolumn{2}{|c|}{ Classical endarterectomy $(n=85)$} & \multirow[b]{2}{*}{$p^{\dagger}$} \\
\hline & $\mathrm{n}$ & $\%$ & $\mathrm{n}$ & $\%$ & \\
\hline Diabetes & 7 & 25.9 & 35 & 41.2 & 0.154 \\
\hline Hypertension & 19 & 70.4 & 64 & 75.3 & 0.611 \\
\hline Hyperlipidemia & 11 & 40.7 & 39 & 45.9 & 0.640 \\
\hline Chronic renal failure & 5 & 18.5 & 7 & 8.2 & 0.157 \\
\hline $\begin{array}{l}\text { Presence of stenosis in the contralateral } \\
\text { carotid artery }\end{array}$ & 14 & 51.9 & 47 & 55.3 & 0.754 \\
\hline Presence of other peripheral artery disease & 5 & 18.5 & 16 & 18.8 & 0.972 \\
\hline CAD & & & & & 0.778 \\
\hline Absence & 5 & 18.5 & 11 & 12.9 & \\
\hline Medical follow-up & 8 & 29.6 & 27 & 31.8 & \\
\hline Stent implanted & 2 & 7.4 & 10 & 11.8 & \\
\hline Pre-CABG performed & 5 & 18.5 & 10 & 11.8 & \\
\hline Simultaneous CABG & 7 & 25.9 & 27 & 31.8 & \\
\hline Previous CVA & & & & & 0.354 \\
\hline Absence & 17 & 63.0 & 40 & 47.1 & \\
\hline Presence (no sequelae) & 5 & 18.5 & 23 & 27.1 & \\
\hline Presence (with sequelae) & 5 & 18.5 & 22 & 25.9 & \\
\hline Other diseases & & & & & 0.117 \\
\hline Absence & 16 & 59.3 & 52 & 61.2 & \\
\hline Non-ischemic cardiac diseases & 2 & 7.4 & 12 & 14.1 & \\
\hline Chronic lung diseases & 5 & 18.5 & 8 & 9.4 & \\
\hline Other systemic diseases & 2 & 7.4 & 8 & 9.4 & \\
\hline NICD + Chr. LD & 2 & 7.4 & 0 & 0 & \\
\hline Chr. LD + OSD & 0 & 0 & 4 & 4.7 & \\
\hline NICD + Chr. LD & 0 & 0 & 1 & 1.2 & \\
\hline
\end{tabular}




\begin{tabular}{|c|c|c|c|c|c|c|c|}
\hline & & Int & $\begin{array}{l}\text { able } 3 \\
\text { erative data }\end{array}$ & & & & \\
\hline & Modi & eversi & eethod $(n=27)$ & Class & endart & tomy $(n=85)$ & \\
\hline & $\mathrm{n}$ & $\%$ & Mean \pm SD & $\mathrm{n}$ & $\%$ & Mean $\pm S D$ & $p$ \\
\hline Degree of lesion (\%) & & & $0.8 \pm 0.1$ & & & $0.8 \pm 0.1$ & $0.490 \dagger$ \\
\hline Cross-clamp time (min) & & & $15.4 \pm 2.8$ & & & $17.3 \pm 6.7$ & $0.470 \dagger$ \\
\hline Operation & & & & & & & $0.784 \neq$ \\
\hline Right carotid endarterectomy & 11 & 40.7 & & 29 & 34.1 & & \\
\hline Left carotid endarterectomy & 9 & 33.3 & & 29 & 34.1 & & \\
\hline CABG + endarterectomy & 7 & 25.9 & & 27 & 31.8 & & \\
\hline Use of graft & & & & & & & $0.425 \ddagger$ \\
\hline Not used & 25 & 92.6 & & 70 & 82.4 & & \\
\hline Native graft & 1 & 3.7 & & 6 & 7.1 & & \\
\hline Artificial graft & 1 & 3.7 & & 9 & 10.6 & & \\
\hline Use of shunt & & & & & & & $0.001^{*}$ \\
\hline Used & 0 & 0 & & 30 & 35.3 & & \\
\hline Not used & 27 & 100 & & 55 & 64.7 & & \\
\hline
\end{tabular}

\begin{tabular}{|c|c|c|c|c|c|}
\hline \multicolumn{6}{|c|}{$\begin{array}{c}\text { Table } 4 \\
\text { Intraoperative and early postoperative data }\end{array}$} \\
\hline & \multicolumn{2}{|c|}{ Modified eversion method $(n=27)$} & \multicolumn{2}{|c|}{ Classical endarterectomy $(n=85)$} & \multirow[b]{2}{*}{$p^{\dagger}$} \\
\hline & $\mathrm{n}$ & $\%$ & $\mathrm{n}$ & $\%$ & \\
\hline Perioperative results & & & & & 0.365 \\
\hline Good & 26 & 96.3 & 80 & 94.1 & \\
\hline Wound hematoma & 1 & 3.7 & 1 & 1.2 & \\
\hline Discharged with sequela & 1 & 3.7 & 1 & 1.2 & \\
\hline Exitus & 0 & 0 & 4 & 4.7 & \\
\hline Early results $(n=62)$ & & & & & 0.263 \\
\hline Good & 20 & 95.2 & 40 & 97.6 & \\
\hline Advanced stenosis & 1 & 4.7 & 1 & 2.4 & \\
\hline
\end{tabular}

disease $(p>0.05)$. According to the method used in the operation, there was no statistically significant difference between the rates of previous CVA ( $>0.05)$ (Table 2).

There was no statistically significant difference between the mean lesion degrees according to the method used in the operation $(p>0.05)$. Although the mean cross-clamp times were shorter in the MEE compared to the method used in the classical CEA, no statistically significant difference was found $(p>0.05)$. There was no statistically significant difference between the graft use rates according to the method used in the operation ( $p>0.05)$. Since shunts were not used in the MEE, there was a statistically significant difference between the rates of shunt use between the groups $(\mathrm{p}<0.01)$ (Table 3$)$.

There was no statistically significant difference between the intraoperative results according to the method used in the operation $(p>0.05)$. While the results of the intraoperative period were good in 26 (96.3\%) patients in the MEE group, subcutaneous hematoma occurred in one $(3.7 \%)$ patient and treated by revision, while one (3.7\%) patient was discharged with sequelae. This case with sequelae had contralateral CAS; CEA combined with coronary artery bypass grafting $(\mathrm{CABG})$ was applied to the patient, and CEA was performed under deep hypothermia. The carotid ultrasound of the patient was normal. The 
intraoperative results were good in 80 (94.1\%) patients in the CEA group, while one (1.2\%) patient developed subcutaneous hematoma which was treated by revision and one (1.2\%) patient case was discharged with sequelae. Four (4.7\%) patients died as a result of postoperative CVA. No graft was used in any of these cases. Shunt was used in the patient who was discharged with sequelae. Bilateral carotid arteries were normal on control carotid DUS. Only CEA was performed in one of the patients who died, and a combination of CEA and CABG was performed in the other patients. Endarterectomy was performed in these patients under deep hypothermia and no shunt was used. There was no statistically significant difference between early restenosis rates according to the method used in the operation ( $p>0.05)$. The early results were good in 20 (95.2\%) patients in the MEE group, while only one (4.7\%) patient had severe stenosis. The early results were also good in 40 (97.6\%) patients in the classical CEA group, while severe stenosis was observed in one (2.4\%) patient (Table 4).

\section{DISCUSSION}

The incidence of CAS is substantially high in the elderly population as in the other peripheral artery diseases. In the Rotterdam study, stenosis between 16 and $49 \%$ was found in 3\% of patients over the age of 55 years, and stenosis over $50 \%$ was found in $1.4 \% .{ }^{[9]}$ Similarly, in the Tromso study, the prevalence of CAS in men over the age of 50 years was found to be 4.2 , while it was $2.7 \%$ in women, indicating a statistically significant difference between the sexes. ${ }^{[10]}$ In the Framingham study, in $40 \%$ of 75 -year-old men, a narrowing of more than $10 \%$ was found. ${ }^{[11]}$ The disease, which is very widespread in the elderly, has a high cost to the society, the individual, and the environment. Considering the monetary cost, the total annual cost of stroke in the United States is estimated as $\$ 65.5$ billion. ${ }^{[12]}$ The total annual cost of stroke in the Europe is estimated as $€ 27$ billion. ${ }^{[12]}$ Carotid artery disease is the cause of an average of $20 \%$ of these strokes.

The necessity of the CEA method in advanced CAS, its priority over other treatment modalities, and the variety of surgical techniques applied urge us to find the most ideal surgical method. Before starting CEA, it is necessary to decide the anesthesia type of the operation. The randomized Local Anesthesia versus General Anesthesia for Carotid Surgery (GALA) study showed no significant difference between the general (4.8\%) and local (4.5\%) anesthesia in terms of intraoperative mortality, stroke or myocardial infarction. ${ }^{[13]}$ In our clinic, general anesthesia method is routinely used. Since the arteriotomy performed in classical CEA includes CCA and ICA and the wide area can be reached in the CEA procedure, there is no problem in accessing the distal and proximal ends. However, there may be problems in finding the correct plane during the CEA procedure. The plaque may rupture in pieces rather than as a whole, leading to weakening of the vessel wall in some areas, remaining plaque remnants in some areas, and forming a rough surface. After CEA is completed, when it comes to the closure stage, it may be necessary to use a native or synthetic patch in some cases, as the lumen may narrow, while performing primary repair. The Cochrane database review focused on seven studies. ${ }^{[14]}$ The results of 1,127 patients and 1,307 operations were examined, and the results of primary repair, vein grafts, and other grafts were analyzed. Although the data in the analyzed studies were insufficient and included methodological errors, the results obtained from the examined studies concluded that the risk of stroke was lower in the patch plasty group compared to the primary repair group, and arterial occlusion was lower in the patch plasty group in long-term follow-up. However, unlike retrospective analyses, randomized clinical studies revealed no statistically significant difference between these groups. Nevertheless, the evidence obtained is that the application of carotid patch plasty reduces the risk of occlusion and restenosis, as well as the combined stroke and mortality rate. ${ }^{[15]}$ Considering the results of the materials used in patch plasty $\left(\right.$ Dacron $^{\circledR}$, polytetrafluoroethylene, or autologous), the difference between them was found to be small. ${ }^{[16,17]}$ In our patient groups, there was no statistically significant difference in terms of the use of patches in either group. However, patches were not used in patients who developed mortality, morbidity, and late restenosis. In the eversion technique, when the ICA is completely transected from the bifurcation, the plaque is everted and removed from the ICA during CEA. Thus, no more tissue remains in the vessel wall, although problems may occur in reaching the proximal end point of the CCA and the distal end of the ECA. While the ICA is fully transected from the bifurcation, there is a possibility that adjacent nerves, particularly the Vagus nerve, can be damaged. In this method, the proximal mouth of the ICA is enlarged and sutured again to the bifurcation point 
and, thus, it does not cause any surgical stenosis in the vessel lumen. In the Cochrane study, the eversion technique caused less restenosis than other techniques, the results obtained from other studies were similar, and no significant difference was observed in terms of neurological deficits between the eversion technique and classical CEA techniques. ${ }^{[18,19]}$

Although shunts are not used in the eversion technique, some surgeons have advocated the use of shunts, particularly in patients with an occluded contralateral carotid artery. ${ }^{[20]}$ In the randomized International Carotid Stenting Study (ICSS) study, patients who underwent $\mathrm{CAE}$ and carotid stenting were applied diffusion-weighted magnetic resonance imaging to evaluate postoperative early (one to three days) acute ischemia, while fluid-attenuated inversion recovery investigation was conducted to evaluate late (four to six weeks) permanent brain damage. ${ }^{[21]}$ Percentages of new ischemic events in the patients with early carotid stenting and in patients who underwent CAE were $46.4 \%$ and $14.1 \%$, respectively. Most of the patients remained asymptomatic. In the late period, permanent cerebral abnormalities were detected to be $30 \%$ in the carotid stenting group and $8 \%$ in the CEA group. ${ }^{[22]}$ Based on these results, it should be kept in mind that any further manipulation into the ICA may have more negative consequences than expected. In the European Carotid Surgery Trial (ECST) involving 1,729 patients, no statistically significantly positive results were found in terms of the use of shunts. ${ }^{[23]} \mathrm{On}$ the other hand, controlling the adequacy of cerebral perfusion with any non-invasive methods before deciding to use a shunt may prevent unnecessary usages. In the study of Ozer and Ceyran, ${ }^{[24]}$ cerebral perfusion could be non-invasively determined using near infrared spectroscopy. Continuous measurement of cerebral oxygenation can be achieved by cerebral oximeter and more than 20\% decrease compared to baseline levels shows a troublesome at cerebral perfusion. Conversely, preserved cerebral oxygen saturations after clamping carotid artery may give an insight that the adequacy of cerebral perfusion. Thus, unnecessary usage of shunts may be restricted.

In the MEE technique applied in our center, since, in an ideal plane, CEA was performed in the media adventitia junction and as a complete block (CCA, ECA and ICA complete), there were no cases such as thinning of the vessel wall and tissue debris in the wall. The time of procedure was not long, as the method was practical and no extra-intervention (such as plate fixation or shunt placement) was applied. Of note, in the MEE method, cross-clamp time was shorter than classical CEA, consistent with previous studies. ${ }^{[25]}$

The main limitations to the present study are its retrospective nature with a relatively small sample size, the lack of mid- and long-term follow-up data, and lack of routine intraoperative monitoring of cerebral perfusion.

In conclusion, CEA is the primary treatment option in the light of available data in advanced CAS. Different techniques are used in this treatment. In our clinic, classical CEA and MEE are successfully applied as carotid artery surgery. In our study, we found no statistically significant difference between the two methods in terms of intraoperative mortality, morbidity, and restenosis rates. Based on these results, we suggest that the MEE applied in our clinic is as effective as classical CEA. We believe that this method should be kept in mind as an alternative to the classical CEA technique.

\section{Declaration of conflicting interests}

The authors declared no conflicts of interest with respect to the authorship and/or publication of this article.

\section{Funding}

The authors received no financial support for the research and/or authorship of this article.

\section{REFERENCES}

1. Grau AJ, Weimar C, Buggle F, Heinrich A, Goertler M, Neumaier S, et al. Risk factors, outcome, and treatment in subtypes of ischemic stroke: the German stroke data bank. Stroke 2001;32:2559-66.

2. Barnett HJ, Taylor DW, Eliasziw M, Fox AJ, Ferguson GG, Haynes RB, et al. Benefit of carotid endarterectomy in patients with symptomatic moderate or severe stenosis. North American Symptomatic Carotid Endarterectomy Trial Collaborators. N Engl J Med 1998;339:1415-25.

3. Randomised trial of endarterectomy for recently symptomatic carotid stenosis: final results of the MRC European Carotid Surgery Trial (ECST). Lancet 1998;351:1379-87.

4. Mayberg MR, Wilson SE, Yatsu F, Weiss DG, Messina L, Hershey LA, et al. Carotid endarterectomy and prevention of cerebral ischemia in symptomatic carotid stenosis. Veterans Affairs Cooperative Studies Program 309 Trialist Group. JAMA 1991;266:3289-94.

5. Rothwell PM, Eliasziw M, Gutnikov SA, Fox AJ, Taylor DW, Mayberg MR, et al. Analysis of pooled data from 
the randomised controlled trials of endarterectomy for symptomatic carotid stenosis. Lancet 2003;361:107-16.

6. Inzitari D, Eliasziw M, Gates P, Sharpe BL, Chan RK, Meldrum HE, et al. The causes and risk of stroke in patients with asymptomatic internal-carotid-artery stenosis. North American Symptomatic Carotid Endarterectomy Trial Collaborators. N Engl J Med 2000;342:1693-700.

7. Halliday A, Mansfield A, Marro J, Peto C, Peto R, Potter $\mathrm{J}$, et al. Prevention of disabling and fatal strokes by successful carotid endarterectomy in patients without recent neurological symptoms: randomised controlled trial. Lancet 2004;363:1491-502.

8. Halliday A, Harrison M, Hayter E, Kong X, Mansfield A, Marro J, et al. 10-year stroke prevention after successful carotid endarterectomy for asymptomatic stenosis (ACST1): a multicentre randomised trial. Lancet 2010;376:1074-84.

9. Bots ML, Breslau PJ, Briët E, de Bruyn AM, van Vliet HH, van den Ouweland FA, et al. Cardiovascular determinants of carotid artery disease. The Rotterdam Elderly Study. Hypertension 1992;19:717-20.

10. Mathiesen EB, Joakimsen O, Bønaa KH. Prevalence of and risk factors associated with carotid artery stenosis: the Tromsø Study. Cerebrovasc Dis 2001;12:44-51.

11. Murabito JM, Evans JC, D’Agostino RB Sr, Wilson PW, Kannel WB. Temporal trends in the incidence of intermittent claudication from 1950 to 1999. Am J Epidemiol 2005;162:430-7.

12. Di Carlo A. Human and economic burden of stroke. Age Ageing 2009;38:4-5.

13. GALA Trial Collaborative Group, Lewis SC, Warlow CP, Bodenham AR, Colam B, Rothwell PM, et al. General anaesthesia versus local anaesthesia for carotid surgery (GALA): a multicentre, randomised controlled trial. Lancet 2008;372:2132-42.

14. Criqui $\mathrm{MH}$, McClelland RL, McDermott MM, Allison MA, Blumenthal RS, Aboyans V, et al. The ankle-brachial index and incident cardiovascular events in the MESA (Multi-Ethnic Study of Atherosclerosis). J Am Coll Cardiol 2010;56:1506-12.

15. Ruehm SG, Goyen M, Barkhausen J, Kröger K, Bosk S, Ladd ME, et al. Rapid magnetic resonance angiography for detection of atherosclerosis. Lancet 2001;357:1086-91.
16. İyigün T, Kyaruzi M, Timur B, İyigün M, Aydın Ü. Our midterm restenosis results using patch angioplasty closure versus primary closure in patients undergoing carotid endarterectomy: A comparative study. Turk J Vasc Surg 2019;28:19-23.

17. Şahin A, Dernek S. Is primary closure still a reliable technique in carotid endarterectomy? Cardiovasc Surg Int 2020;7:169-169.

18. Zhu Z, Yu W. Update in the treatment of extracranial atherosclerotic disease for stroke prevention. Stroke Vasc Neurol 2019;5:65-70.

19. Chrysochou C, Kalra PA. Epidemiology and natural history of atherosclerotic renovascular disease. Prog Cardiovasc Dis 2009;52:184-95.

20. Baker WH, Littooy FN, Hayes AC, Dorner DB, Stubbs D. Carotid endarterectomy without a shunt: the control series. J Vasc Surg 1984;1:50-6.

21. International Carotid Stenting Study investigators, Ederle J, Dobson J, Featherstone RL, Bonati LH, van der Worp HB, et al. Carotid artery stenting compared with endarterectomy in patients with symptomatic carotid stenosis (International Carotid Stenting Study): an interim analysis of a randomised controlled trial. Lancet 2010;375:985-97.

22. Bonati LH, Jongen LM, Haller S, Flach HZ, Dobson J, Nederkoorn PJ, et al. New ischaemic brain lesions on MRI after stenting or endarterectomy for symptomatic carotid stenosis: a substudy of the International Carotid Stenting Study (ICSS). Lancet Neurol 2010;9:353-62.

23. Bond R, Warlow CP, Naylor AR, Rothwell PM; European Carotid Surgery Trialists' Collaborative Group. Variation in surgical and anaesthetic technique and associations with operative risk in the European carotid surgery trial: implications for trials of ancillary techniques. Eur J Vasc Endovasc Surg 2002;23:117-26.

24. Özer T, Ceyran H. Cerebral oxymeter changes and clinical outcomes at different hypothermic levels during cardiopulmonary bypass in pediatric patients. Koşuyolu Heart J 2018;21:217-24.

25. McBride R, Porter J, Al-Khaffaf $\mathrm{H}$. The modified operative technique of partial eversion carotid endarterectomy. J Vasc Surg 2017;65:263-6. 